\title{
DIFFICULTIES IN SUSTAINABILITY AND LAND UTILISATION
}

\section{Róbert MAGDA}

\author{
Károly Róbert College, Gyöngyös, Hungary
}

The aim of this paper is to show the economic importance of the land sustainability. This topic is very complex because it is relevant universally - the land utilisation has an industrial, agricultural production, energy and environmental security aspect. The focus of the analysis is the relationship between land usage, scarcity and sustainability.

Keywords: land usage, scarcity, sustainability

\section{Introduction}

Although the world's resource base is limited, it contains a complex and interrelated set of ecosystems that are currently exhibiting signs of fragility. It is increasingly questioned whether the global economic system can continue to grow without undermining the natural system, which is its ultimate foundation.

For the moment we can say that the problem of sustainability is how to alleviate poverty without negatively affecting the natural environment in such a way that future economic prospects would not suffer.

The current global economic crisis may easily become the longest in three generations. If trust in finance and economy does not return rapidly, economic reform, socio-economic growth and political stability will suffer. While some confidence in the financial system will return in due course, a new financial architecture is required to strengthen the global economy and increase economic and financial fairness. In this connection, it is critical that the needs for global food and environmental security are taken into account. World population growth is the biggest trend-making factor: 70 to 80 million more people a year, exceeding 7 billion by 2012. Population growth creates a rapidly growing demand for food products including animal feed, which arises from increasing meat consumption. Other major global trends are globalization and urbanization. Moving production to the most competitive regions causes the food trade to become more liberalized and more concentrated as well. Growing energy demand and climate change will also influence food production. Agriculture contributes to emissions of GHG into the environment and also suffers or benefits from changing climates, depending on climatic zones. The additional challenges are increasing market volatility resulting from yield and stock fluctuations and consumer sensitivity to food quality, safety and price. Finally I raise the question of who will pay for agricultural public services provided by the land managers that the market does not pay for, such as rural landscape maintenance, environmental protection of biodiversity or animal welfare. These challenges are aggravated by global irresponsibility related to food security, water and environmental sustainability and energy security (Magda, 2011).

Joseph Stiglitz and Nicholas Stern made a joint appeal to use the financial crisis as an opportunity to lay the foundations for a new wave of growth based on technologies for a low carbon economy (Financial Times, 2009). The investments would drive growth over the next two or three decades and ensure its sustainability. They noted that "providing a strong, stable carbon price is the single policy action that is likely to have the biggest effect in improving economic efficiency and tackling the climate crisis." Lord Stern calculated that governments should spend at least $20 \%$ of their stimulus on green measures to achieve emission targets (Stern, 2006).

\section{Results and Discussion}

\section{Scarcity and Land Utilization}

The environmental resource scarcity issues are entirely real. As a result of climate changes, most agricultural patterns may become disrupted and the poorest countries are the most vulnerable to such disruptions. Over the long term, environmental security is the mirror image of the food security, since we have no food without substantial clean water resources, productive soils and appropriate climate. Climate change subjects all businesses and society in general to cumulative, long-term risk. The failure of agriculture alone would lead to widespread hunger in developing countries and mass migration of people (half a billion according to the United Nations), mostly to developed countries.

In this period when the world economy has been decreasing rapidly, it is necessary to analyse different possibilities, which can help us change this negative tendency and find the right way. So we need to valuate our resources from the human capital to the natural resources. That is the reason why I focus on one of the most important resources, namely arable land.

The land as an economic resource is mostly utilised by agriculture. Land usage occurs in a competitive environment (market competition) and economic factors are primary for all the farmers. However, it should not be forgotten that the land is a natural resource at the same time. No matter who the owner of a given piece of land is, the land is a part of the national wealth and it must be used in an optimal way. Regulation of the land use activities is a governmental task (e. g. environmental protection).

In my opinion, land usage can be defined as a fine balance between sophisticated and interrelated activities, a precise order and harmony of biological, physical and chemical processes. This system of relations can only be described by using the rules of system theory and its adaptation to the specific conditions of land usage. It is important that the land usage is defined on the basis of system theories by the fact that the whole system and the relationship between certain elements must be clearly specified and quantification must also be done.

On the one hand, I have to emphasize that the land utilization is a complex category, while the agricultural utilization is only one part of it, 
albeit the most important one. What is more, the present type of agricultural land usage gives us examples which support the fact that this question area cannot be defined on its own, rather in a complex system compared with other land utilization possibilities. It holds true for both micro and macro levels as well. The aim is to find the best solution of land utilization in the most effective way. In a narrow sense, land utilization is part of global utilization, since its use is limited to certain aspects only. Nevertheless, in some cases it is a wider category because it includes those lands which are needed for both the processing and the services industry. Global utilization can provide answers only to questions that are in connection with the comprehensive relations of economical development. We will have to separate the different forms of land usage and point out its extern and internal relationships.

Once the best utilisation has been found, our task is to produce in a sustainable manner. It is especially important nowadays, when we use so much limited resources such as oil, gas and arable land. It is a generally accepted fact that we are borrowing land from our grandchildren, so we must return it unharmed.

\section{Definitions and Meanings of Sustainability}

There is no universally agreed definition of the concept of sustainability. On the contrary, one finds a vast array of definitions, meanings, and interpretations in the literature.

Many writers deduce that sustainability follows from a moral obligation, so that the present generation has a moral obligation to the succeeding. Such an obligation implies that we should not act in ways that jeopardise the chances of the future generations to have equal opportunities to those which are currently enjoyed.

At times, arguments for sustainability seem to have a different basis. Let us suppose that ecological diversity is believed to be an important objective in its own right. In this case, economic activity, which threatens to reduce biodiversity, would be intrinsically undesirable. We should organise our behaviour so as to avoid serious ecological disruption, to make economic activity more consistent with ecological diversity. Once again, there are different ways in which an ecological case for sustainability could be argued, possibly in terms of ecological stability or integrity rather than diversity. Nevertheless, any such arguments remain fundamentally ethical. If an ecological objective is to be pursued, it must be placed on ethical principle.

\section{Sustainable Development}

In my opinion, a reasonable definition of sustainable development might be as follows: it involves maximising the net benefits of economic development, subject to maintaining the services and the quality of natural resources over time. Mankind is directly influenced by the loss of biodiversity. The right to development implies the right to improvement and advancement of economic, social, cultural and political conditions. Improvement of global quality of life means the implementation of change, which ensures a life of dignity for every person, as well as life in a society that respects and helps realize all human rights. These changes must include the eradication and alleviation of widespread conditions of poverty, unemployment and inequitable social conditions. Sustainable development ensures the wellbeing of humans by integrating social development, economic development, environmental conservation and protection.

Social development implies that the basic needs of the human being are met through the implementation and realization of human rights. Basic needs include access to education, health services, food, housing, employment and the fair distribution of income. Social development promotes democracy to bring about the participation of the public in determining policy, as well as creating an environment for responsible governance. Social development empowers the poor to expand their use of available resources in order meet their own needs and change their own lives. Special attention is paid to ensure equitable treatment of women, children, people of indigenous cultures, people with disabilities and all members of populations considered most vulnerable to the conditions of poverty.

Economic development expands the availability of work and the ability of individuals to secure an income to support themselves and their families. Economic development includes industry, sustainable agriculture, as well as integration and full participation in the global economy. Social and economic developments reinforce and depend on one another for full realization.

It is impossible to separate the well-being of the humans from the well-being of the earth. Therefore a truly sustainable development places just as much importance on the protection of the Earth as on its resources. International documents that include the environmental aspect of development affirm and reaffirm that "human beings are at the centre of concern for sustainable development. They are entitled to a healthy and productive life in harmony with nature...." As the goal of sustainable development is to permanently improve the living conditions of human beings, social and economic developments must be carried out in a way that is environmentally and ecologically sound, ensuring the continual rejuvenation and availability of natural resources for future generations.

Active participation in sustainable development ensures that those who are affected by the changes are the ones determining the changes. The result is the enjoyment and sharing of the benefits and products generated by the change. Participation is not exclusive, ensuring equitable input, selfdetermination and empowerment of both genders and all races and cultural groups.

\section{Poverty and Sustainable Development}

Many people live in the conditions which do not meet reasonable standards. This is particularly true for people living in the poor nations of the world. However, it is by no means restricted to them. Even in the richest countries, there are income and wealth inequalities, so that many people live in conditions of material and social deprivation. For many years it was thought that the eradication of poverty required well-designed development programmes that were largely independent of considerations related to the natural environment. The goal of economic and political debate was to identify growth processes that could allow living standards to rise continually. Economic development and nature conservation were seen as quite distinct and separate problems.

Perspectives have changed significantly since the 1970s. While the pursuit of economic growth and development continues, it has been recognised that the maintenance of growth has an important environmental dimension. During the 1970s, a concern for sustainability began to appear on the international political agenda. The common theme was the interrelationship between poverty, economic development and the state of the natural environment.

On the supply side, the principle of limited food production capacity is exemplified by the fact that the principal grains exporters - the United States, Canada, Australia, Argentina, and the European Union - seem to have reached a plateau. Together, they produce about 85 percent of the world's grain exports.

The notion of developing comprehensive policies that promote sustainable use of natural resources, maintain resource production capacity and prevent resource degradation was subsequently adopted by various UN conferences and supported by many international development 
agencies. This is especially important for underdeveloped nations with the least discretionary income to purchase essential food commodities, to prevent declining production capacity or to reverse trends in environmental degradation. Therefore they are likely to face spiralling effects of economic decline, as depicted below (Figure 1).

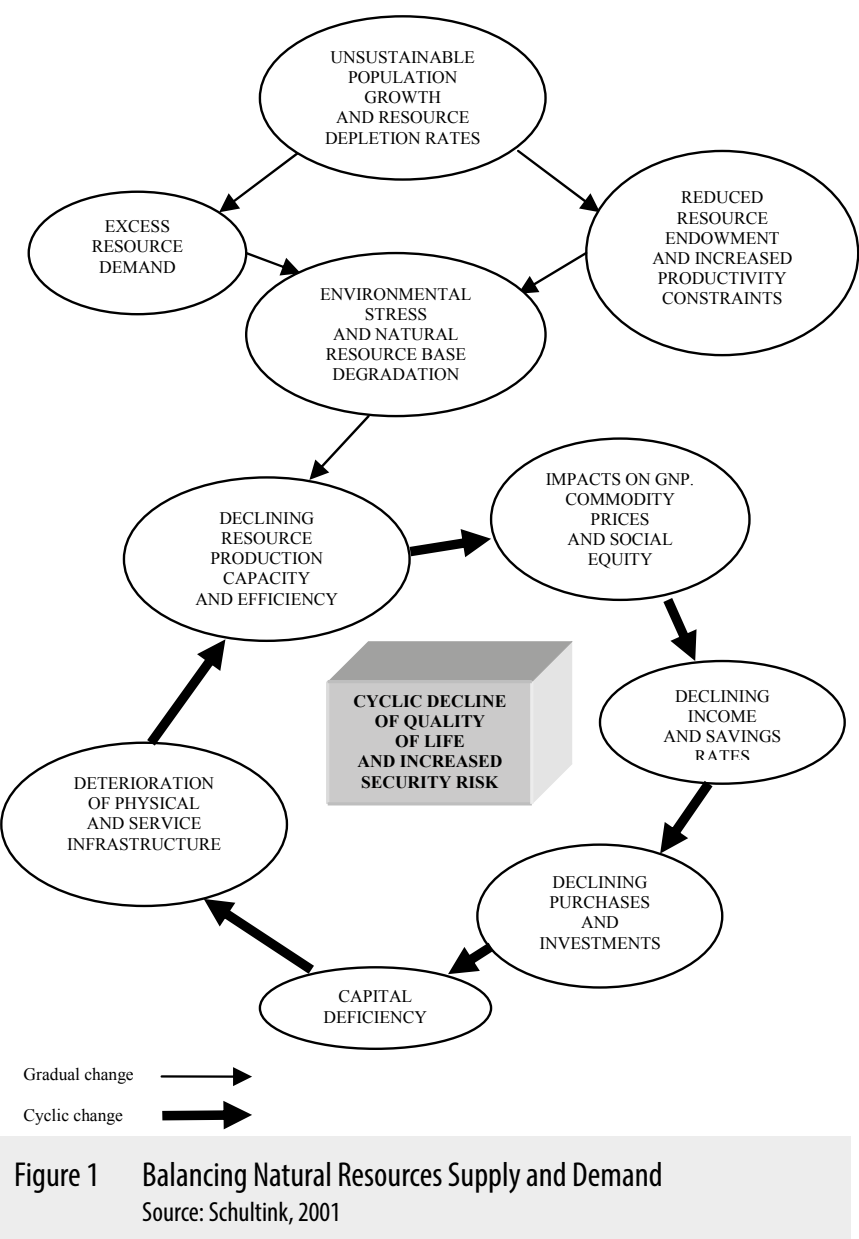

\section{Land Utilisation and Sustainability}

When we focus on sustainability in relation to the land, we need to think in the long run. The basic condition for sustainable agriculture is that it must be in harmony with the environment, which means that the land use should be optimised for production at an intensity level that may cause no harm whatsoever.

Similarly, in The Limits to Growth (Meadows et al., 1972), the results of global computer analysis compared the rates of population and industrial growth to declining natural resources. It concluded that modern industrial society might not survive this disparity within the next century. Critics argued that this scenario was unduly pessimistic, since the study failed to take the ingenuity of evolving science and technology into account. Others argued that it provided an early warning, a wake-up call indicating that if present growth trends of world population, industrialization, pollution, food production, and resource depletion continued unchanged, a potential dramatic, possibly uncontrollable decline in both population and production capacity would take place.

In their research we can find many problems but I would like to focus on only five of them which are in close relationship with land utilisation.

First of all, population growth must be mentioned. Analysing the table, I can see a huge increase in the number of the world population which will be more than 3.5 times bigger in 2050 than it was in 1950. It will present a great problem because nowadays about 1 billion people are starving and this number will increase in the future. Table 2 reveals that the biggest problem occurs in the case of the less and least developed countries, where this increase is considerably higher than the average (Table 1).

\section{Table 1 World population (1950-2050)}

\begin{tabular}{|l|c|c|c|c|}
\hline & 1950 & 2000 & 2003 & 2050 \\
\hline Total (million) & 2,519 & 6,071 & 6,301 & 8,919 \\
\hline Developed countries & 813 & 1,194 & 1,203 & 1,220 \\
\hline Less developed countries & 1,706 & 4,877 & 5,098 & 7,639 \\
\hline Least developed countries & 200 & 668 & 718 & 1,675 \\
\hline
\end{tabular}

Source: UN (2003) World Population Prospects: The 2002 Revision. Highlights. New York: United Nations.

Less developed countries: African and Asian countries instead of Japan, Latin America and Caribbean region

Developed countries: European countries, North America, Australia, New Zealand and Japan

The second problem is the increase in natural resource extraction. It started in the $18^{\text {th }}$ century after the industrial revolution and has increased step by step, but with a higher rate. In table 3 we can see the production of the primary energy in the last decade. In the EU countries, including Hungary, it was decreasing by a small proportion in this period, while the increase in China during the same period was approximately $70 \%$, which was shocking. The production in the USA and Japan was fairly even.

Table 2 Primary energy production (billion tons, oil equivalence)

\begin{tabular}{l|c|c|c|c|c|c|} 
& 2000 & 2001 & 2003 & 2005 & 2007 & 2010 \\
\hline EU-27 & 933.0 & 932.2 & 926.4 & 890.2 & 859.5 & 878.3 \\
\hline USA & $1,678.8$ & $1,699.9$ & $1,634.5$ & $1,629.9$ & $1,665.2$ & $1,740.9$ \\
\hline Japan & 105.8 & 104.7 & 84.0 & 99.8 & 90.5 & 95.0 \\
\hline China & $1,073.0$ & $1,104.5$ & $1,331.3$ & $1,640.9$ & $1,814.0$ & $2,186.4$ \\
\hline Hungary & 11.32 & 10.8 & 10.7 & 10.4 & 10.2 & 10.9 \\
\hline & $\begin{array}{l}\text { Source: } \\
\text { data_value_2010+wbapi_data_value+wbapi_data_value-last\&sort=asc }\end{array}$
\end{tabular}

The third problem is the expansion of the industrial production (electricity production is presented in table 3 ) which is in close relationship to the increase of the natural resources production. Electricity is very important because it is the basis of all the other industries.

Table 3 Gross electricity production (billion kWh)

\begin{tabular}{|l|c|c|c|c|c|c|}
\hline & 2000 & 2001 & 2003 & 2005 & 2007 & 2010 \\
\hline EU-27 & $3,020.9$ & $3,108.1$ & $3,216.0$ & $3,308.9$ & $3,361.7$ & $3,332.1$ \\
\hline USA & $3,990.5$ & $3,924.1$ & $4,075.8$ & $4,257.4$ & $4,348.9$ & $4,325.9$ \\
\hline Japan & $1,057.9$ & $1,039.7$ & $1,082.6$ & $1,133.6$ & $1,133.7$ & $1,145.3$ \\
\hline China & $1,368.5$ & $1,434.6$ & $1,905.2$ & $2,474.7$ & $3,277.7$ & $4,206.5$ \\
\hline Hungary & 35.2 & 36.4 & 34.1 & 35.8 & 40.0 & 37.4 \\
\hline
\end{tabular}

Source: http://en.wikipedia.org/wiki/List_of_countries_by_electricity_production

The fourth problem is the environmental pollution which has increased to a great extent. All three factors, population growth, growth of the natural resources and industrial production, generate environmental pollution on their own. However, since they cumulate, a higher increase in this sphere can be found than in the others. 
Last but not least, we could see a great decrease in the territory of the agricultural areas all over the world except for China. It is very dangerous because the population has increased in a high ratio and thus more territories are needed for producing basic materials for the food industry (Table 4).

Table 4 Agriculture area (1,000 ha)

\begin{tabular}{l|c|c|c|c|c|} 
& 2000 & 2001 & 2003 & 2005 & 2007 \\
\hline World & $4,960,102.0$ & $4,967,137.1$ & $4,937,312.0$ & $4,945,770.4$ & $4,931,862.0$ \\
\hline Europe & $486,189.0$ & $483,612.6$ & $479,373.0$ & $476,634.4$ & $474,273.5$ \\
\hline USA & $414,399.0$ & $414,944.0$ & $416,902.0$ & $412,878.0$ & $411,158.0$ \\
\hline Japan & $5,258.0$ & $4,793.0$ & $4,736.0$ & $4,692.0$ & $4,650.0$ \\
\hline China & $544,358.0$ & $543,356.0$ & $541,851.0$ & $547,340.0$ & $552,832.0$ \\
\hline Hungary & 5,854.0 & $5,865.0$ & $5,865.0$ & $5,863.0$ & $5,807.0$ \\
\hline
\end{tabular}

These five factors are interconnected. When the population increases, more resources used by the industry must be available. All of these factors generate environmental pollution. When talking about usage of the typically agricultural areas, it is true that in the past years, the quantity and the ratio of agricultural land have been decreasing all over the world.

Daniella Meadows suggests a zero economic growth in her survey. According to her, it will thus be necessary to decrease growth rates of the first four components by $30-70 \%$ and increase the fifth one by the same ratio.

\section{Conclusion}

Population growth creates a rapidly rising demand for crop products. Increasing energy demand and climate change will also influence food production. Agriculture will contribute to emissions released into the environment and also suffer or benefit from changing climates, depending on climatic zones. The additional challenges are the increasing market volatility resulting from yield and stock fluctuations, as well as consumer sensitivity to food quality, safety and price. The challenges are aggravated by global irresponsibility related to food security, water and environmental sustainability and energy security. The exploitation of our entire ecosystem and the depletion of natural resources have a price that must be paid today to compensate future generations for the losses they will face in the future. The food crisis affected more people more severely than the macroeconomic issue because the populations most affected by sharply rising food prices spend larger shares of their income on food. The global food crisis produced an extraordinary human impact, larger and more adverse than the global financial crisis. Resource productivity should become the core of our next industrial revolution. There are five factors in close relationship with the land utilisation: rapid population growth, increased utilization of natural resources, expansion of industrial production, increase of environmental pollution and the decrease of agricultural areas.
The land as an economic resource is mostly utilized by the agriculture. It can be deemed as an asset, but also as a production factor that serves production and consumption purposes and has three important characteristics: scarcity, immobility and durability. It is an important part of the national wealth and it must be used in an optimal way. The land utilization is a complex category, while the agricultural utilization is only one part of it. However, it may be the most important one. The land utilisation must be in accord with sustainability. The root of the problem is the growing population of the Earth, which will be more than 3.5 times bigger in 2050 than it was in 1950. It will be a great problem, since about 1 billion people are starving nowadays and this number will increase in the future. Only about forty years ago, when the price of oil went up in the world, did economists suddenly realise that some of the resources are limited. In addition, other crucial problems emerged, such as the increase in natural resources extraction, the expansion of industrial production, and the environmental pollution, all of which have been increasing exponentially. It carries a great deal of risks, since the population has increased at such a high ratio and these days, considerably more areas for the basic materials production in the food industry are required than in the past.

\section{References}

FAOSTAT. 2008

MAGDA, R. 2011. A zöldgazdaság és a foglalkoztatás. Európai Tükör XIV évf. 4. sz. 85-96 p. http://www.google.hu/search?q=sustainable+development\&hl=hu\&prmd=imunsb\&tb $\mathrm{m}=\mathrm{isch} \& \mathrm{tb} 0=\mathrm{u} \&$ source $=$ univ\&sa $=\mathrm{X} \& \mathrm{ei}=\mathrm{Nq} 13$ UNKJJIL4QSsplGwDA\&sqi=2\&ved $=$ OCEQQSAQ\&biw $=1680 \&$ bih $=918$

MEADOWS, H et al. 1972. The Limits to Growth. The Club of Rome Report. New York : Universe Books.

SCHULTINK, G. 2001. Comparative Environmental Policy and Risk Assessment: Implications for Risk Communication, International Conflict Resolution and National Security. In: Responding to Environmental Conflicts: Implications for Theory and Practice, Netherlands : Kluwer Publishers, 2001, pp. 95-111.

STERN, N. 2006. Stern Review: The Economics of Climate Change. Cambridge : Cambridge University Press.

UN. 2003. World Population Prospects: The 2002 Revision. Highlights. New York : United Nations.

http://data.worldbank.org/indicator/EG.EGY.PROD.KT.OE?order=wbapi_data_ value_2010+wbapi_data_value+wbapi_data_value-last\&sort=asc

http://en.wikipedia.org/wiki/List_of_countries_by_electricity_production

\section{Contact address:}

Phd associate professor Róbert Magda, Károly Róbert College, Gyöngyös, Mátrai u. 36. Hungary, e-mail: rmagda@karolyrobert.hu 